\title{
Title:
}

\section{DUODENAL LYMPHANGIECTASIAS - THE FIRST SIGN OF PANCREATIC ADENOCARCINOMA}

\section{Authors:}

Filipe Taveira, José Paulo Magalhães, Daniel Brito

DOI: $10.17235 /$ reed.2021.7823/2021

Link: PubMed (Epub ahead of print)

Please cite this article as:

Taveira Filipe, Magalhães José Paulo, Brito Daniel. DUODENAL LYMPHANGIECTASIAS - THE FIRST SIGN OF PANCREATIC ADENOCARCINOMA. Rev Esp Enferm Dig 2021. doi: 10.17235/reed.2021.7823/2021.

This is a PDF file of an unedited manuscript that has been accepted for publication. As a service to our customers we are providing this early version of the manuscript. The manuscript will undergo copyediting, typesetting, and review of the resulting proof before it is published in its final form. Please note that during the production process errors may be discovered which could affect the content, and all legal disclaimers that apply to the journal pertain. 
CC 7823

\section{Duodenal lymphangiectasias - The first sign of pancreatic adenocarcinoma}

Filipe Taveira ${ }^{1}$, José Paulo Magalhães ${ }^{2}$, and Daniel Brito ${ }^{1}$

${ }^{1}$ Department of Gastroenterology, and ${ }^{2}$ Department of Pathology. Instituto Português de Oncologia de Coimbra. Coimbra, Portugal

Correspondence: Filipe Taveira. Department of Gastroenterology. Instituto Português de Oncologia de Coimbra. Av. Bissaya Barreto, 98. 3000-075 Coimbra, Portugal e-mail: fctav@hotmail.com

Dear Editor,

A 41-year-old Caucasian female with a past medical history of pituitary adenoma medicated with cabergoline presented with worsening dyspepsia and unintentional weight loss of $5 \%$. Physical exam and laboratory results were unremarkable for pathological findings. Esophagogastroduodenoscopy revealed an edematous and exuberant lymphangiectasia in the duodenum, with no ulceration or suspected infiltration component (Fig. 1A/B). However, duodenal biopsies revealed infiltration by poorly differentiated carcinoma cells (Fig. 1C/D). Infection and inflammatory/autoimmune causes were ruled out. A CT scan was performed, which revealed a thickened and enlarged pancreas with ill-defined limits, and several intraabdominal adenopathies, raising suspicion of pancreatic lymphoproliferative disease. EUS with FNB were performed, obtaining a pancreatic biopsy sample and a biopsy sample of the larger adenopathy. EUS also revealed an enlarged, non-nodular pancreas and thickened duodenal wall. Mild ascites was detected. Both EUS-guided biopsies were concordant with a diagnosis of highly aggressive carcinoma with a gastric or 
pancreatic-biliary origin (Ki67 > $80 \%$ ). Therefore, a diagnosis of pancreatic adenocarcinoma was assumed (cT4N1Mx). The patient is currently on palliative chemotherapy and remains pauci-symptomatic.

\section{DISCUSSION}

Intestinal lymphangiectasia is a rare finding usually resulting from focal or diffuse dilatation of lymphatics with a risk of loss of lymph fluid, leading to nutritional and immunological abnormalities (1). Several conditions may cause intestinal lymphangiectasia, such as infections (Whipple disease, giardiasis), autoimmune conditions (celiac disease, sarcoidosis), and cancer (mainly lymphoma or abdominal/retroperitoneal carcinoma, as in our case) $(1,2)$. This case of secondary intestinal lymphangiectasia should alert gastroenterologists to the need for histological characterization of this finding, which may, albeit infrequently, be the first sign of malignancy (3).

Informed consent: an informed consent was obtained from the patient for this publication.

Conflicts of interest: the authors declare no conflict of interest. 


\section{REFERENCES}

1. Vignes S, Carcelain G. Increased surface receptor Fas (CD95) levels on CD4+ lymphocytes in patients with primary intestinal lymphangiectasia. Scand J Gastroenterol 2009;44:252-6. DOI: 10.1080/00365520802321220

2. Freeman HJ, Nimmo M. Intestinal lymphangiectasia in adults. World J Gastrointest Oncol 2011;3:19-23. DOI: 10.4251/wjgo.v3.i2.19

3. Bhat $M$, Laneuville $P$, Marliss EB, et al. Secondary intestinal lymphangiectasia due to multiple myeloma. Gastrointest Endosc 2011;74:718-20. DOI: 10.1016/j.gie.2010.09.019 


\section{ENFERMEDADES DIGESTIVAS}

The Spanish Journal of Gastroenterology

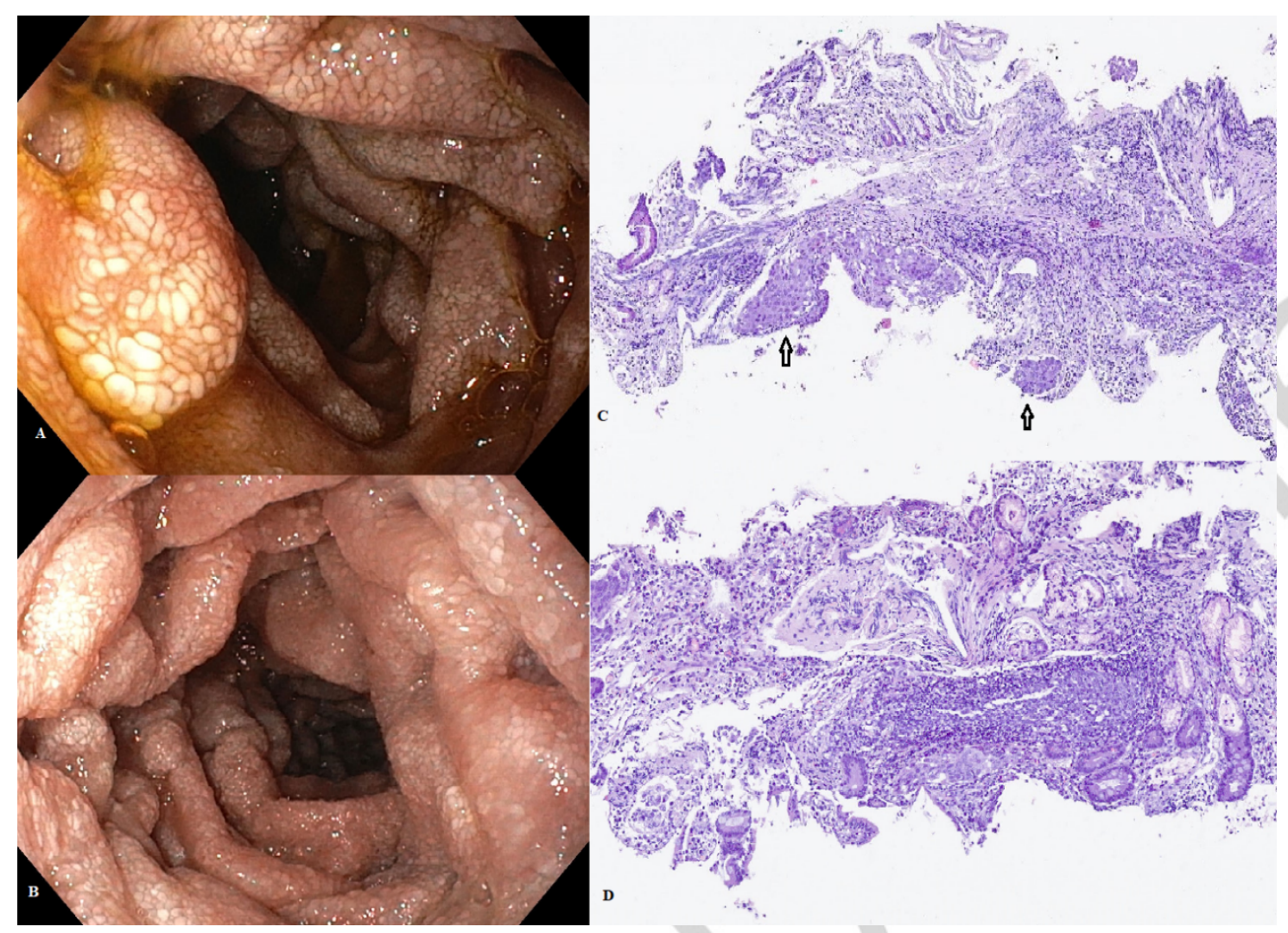

Fig. 1. Upper endoscopy showing multiple lymphangiectasias at D2 (1-A) and D3 (1-B). Histopathology showed areas of carcinoma infiltration in the duodenum (black arrows, 1-C and D) 